\title{
DELIMINATION OF LYMPHATIC FILARIASIS TRANSMISSION RISK AREAS: A SOCIO-ECONOMIC AND GEO-ENVIROMENTAL RISK MODEL ON NORTHEN REGION OF BANGLADESH WITH THE APPLICATION OF GIS
}

DOI: https://doi.org/10.18509/AGB.2020.09

UDC: 616.995.132:[007:528.9:004(549.3)

\author{
Rashed Karim ${ }^{1}$, Sheikh. Monzurul Huq ${ }^{2}$
}

\begin{abstract}
${ }^{I}$ Department of Geography and Environment, Government Saroda Shundori Mohila College, Faridpur, Bangladesh, ${ }^{2}$ Department of Geography and Environment, Jahangirnagsr University, Savar, Dhaka, Bangladesh
\end{abstract}

corresponding author: lec.rashed@gmail.com

\author{
submitted: 08.12 .2019 \\ accepted: 16.03 .2020 \\ published: 15.06 .2020
}

\begin{abstract}
Data integration entails bringing together disparate data sets, which are available on spatial bases, in order that meaningful analyses may be undertaken on them. It mainly involves overlaying different datasets (called layers) and then performing relational and arithmetical operations on them. This might entail, for example, adding, subtracting or multiplying the 'data layers'. The essential capability of GIS is that it can perform in linking a variety of data through building spatial models. International Task Force for Disease Eradication, a task force of world health organization has identified the filariasis is one of the six diseases considered eradicable or potentially eradicable. Filariasis can be defined in a geographical area, as there is local variation in the socio-economic and environmental conditions. If a government has the necessary information on the clustering of filariasis in an area, then a risk zone can be prepared regarding the specific spread of the disease. Delimitation of filariasis is an important requirement to have information on spatial spread and status of the risk of filarial infection, which would facilitate appropriate planning for control/elimination of the disease. This study attempts to define a socio-economic and geo-environmental risk model (SEGERM) for determining the areas of potential transmission of filariasis.
\end{abstract}

Keywords: Geo-Environmental, Risk model, Filariasis, Delimitation, GIS, Risk zones

\section{INTRODUCTION}

Filariasis is a mosquito-borne infectious disease of the human beings. Filariasis is a group of human and animal infectious diseases caused by nematode parasites of the order filrioidea, commonly called filariae (Sasa, 1976). It is a communicable parasitic disease caused by Wuchereria bancrofti, Brugia malayi or Brugia timori that can clinically manifest itself in the form of lymphedema or elephantiasis (WHO, 2001). Filariasis has been identified as a major public health problem and is endemic in over 80 countries (Ngwira et al., 2007). It is the world's second leading cause of long-term disability (WHO, 1995). Currently, more than 1.4 billion people in 73 countries are living in areas where filariasis is transmitted and are at risk of being infected (WHO, 2014b). Approximately 80 percent of these people are living in the following 10 countries: Bangladesh, Democratic Republic of Congo, Ethiopia, India, Indonesia, Myanmar, Nigeria, Nepal, Philippines and the United Republic of Tanzania. It is currently estimated that up to 120 million people are infected with Wuchereria bancrofti in about 83 endemic countries (Michale et al., 1996). Of these 120 million people, about 40 million have evidence of chronic manifestation such as elephantiasis (Ngwira et al. 2007). Globally, an estimated 25 million men suffer from genital disease due to filariasis and over 15 million people are afflicted with lymphoedema (Kanda, 2004).

Filariasis receives much less international attention than other infectious diseases such as Malaria, Tuberculosis (TB) and Acquired Immune Deficiency Syndrome (AIDS) because people do not die as a direct consequence of filariasis. Filariasis is almost entirely a disease of the poor community. According to Sasa (1976), Filariasis is ignored and neglected by the developed world, as the disease is not fatal. Filariasis is seen in developing countries of the world; as a result, the filariasis control programme receives little financial support from the international community. The 
disease exists within the context of poverty and, it makes someone very weak and disable. Continuously growing physically weaken condition contributes significantly to the ongoing incapacity of affected individuals and their families to escape poverty (Durrheim, et al., 2004).

Filariasis infection is usually acquired in childhood causing hidden damage to the lymphatic system. The painful and severely disfiguring visible manifestations of the disease, lymphoedema, elephantiasis and scrotal swelling occur later in life and lead to permanent incapacity. Acute filarial attacks account for significant loss of productive days of risk population. More severely affected people who are physically burdened have social stigma. These patients are not only physically disabled but suffer mental, social and financial losses contributing to social stigma and poverty.

Throughout the year Bangladesh is a country of divergent climatic condition which has a complex influence on physical, economic and social aspects, mainly for its geographic location. Most of the people live in rural areas in this country. A great portion of these rural people is poor. Filariasis is the disease of the poor people. It is totally neglected for more than 50 years in Bangladesh and endemic in 34 out of 64 districts so far (IACIB, 2014). The affected people are generally the poorest and most vulnerable segment of the country.

When geographers conduct disease analysis using techniques such as spatial distribution, spatial association, and prediction, they concentrate mainly on the aspect of where the disease has a tendency to occur. Disease incidents, in general are not randomly distributed throughout the globe. Their distribution is dense at some locations and sparse at others (Fan, 2012) The disease is of interest to

\section{STUDY AREA}

The area of this study is the northern region (Rangpur Division) of Bangladesh. The region is administratively under the Rangpur division, the northernmost division of Bangladesh. The district is bounded on the north by the province of West Bengal Assam state of India, Joypurhat and Bogra districts on the south, Jamalpur district on the east and West Bengal province of India on the west. The study area comprises an area of $16320.26 \mathrm{sq} \mathrm{km}$. The area is located between $25^{\circ} 20^{\prime}$ and $26^{\circ} 37^{\prime}$ north latitudes and between $88^{\circ} 50^{\prime}$ and $89^{\circ} 53^{\prime}$ east longitudes.

The study area is comprised of the alluvial plain, which gently slopes southward with some big rivers. The drainage network is meandering, with broad, smooth, but irregular-shaped ridges crossed geographers for a variety of reasons. They consider a lot of factors to understand the geography of a disease. For example, housing, literacy, toilet facilities, humidity, agriculture activities, sociocultural milieu and overall environment of a particular region influence the incidence of filariasis. A study conducted by the Directorate General of Health Services of Bangladesh has revealed that there was high endemicity of filariasis in Nilphamari, Thakurgaon, Dinajpur, Rangpur, Panchagarh, Kurigram, and Lalmonirhat of Bangladesh (DGHS, 2014). It was estimated that about 70 million were at risk of infection while 1 million people were with various forms of clinical deformity, and another 10 million people are affected with microfilariae (DGHS, 2014).

Although there has been a significant advancement in GIS and its application in disease analysis, its use is rather low in underdeveloped countries like Bangladesh. In Bangladesh there is a paucity in the application of GIS tools to investigate disease causation. In this paper, the filariasis morbidity pattern has been investigated and analysed using the spatial statistical techniques available in GIS. The Hot Spot Analysis, OLS and GWR spatial statistical tools have been employed for exploring the spatial association between filariasis morbidity occurrence and the filariasis predictors. The present article focuses on the filariasis situation of the population of the Northern region (Rangpur Division), relatively backward zones of the country.

This research specifically focuses on morbidity situations due to filariasis, the physical environment and socio-economic aspects to define a socioeconomic and geo-environmental risk model (SEGERM) for determining the areas of potential transmission of filariasis

by numerous, broad shallow channels that frequently branch out and reconnect. There is a considerable variation in the type and nature of soil belonging to different parts of the study area. Old Himalayan Piedmont Plain has deep and rapidly permeable sandy loams and sandy clay loams are predominant in the region. The region is exposed to cold waves during winter due to its proximity to the Himalayas. Summer is the hottest season of the year and it starts from early March and continues till the middle of June. In summer, the average maximum and minimum temperatures in summer are about $390 \mathrm{c}$ and $70-100 \mathrm{c}$ during the winter. The region has a total number of 15665000 population of which 7824000 male and 7840000 female and the population growth rate is 1.2 (BBS, 2011a). 


\section{METHODS}

This study used quantitative methods. Quantitative data on filariasis morbidity, socio-economic and environmental issues (based on a literature review) were collected from different sources.

Demographic data were collected from the population census 2011 report (B. B. S., 2011a). Data on total population, number of male and female, population density, literacy rate were collected from the population and housing census published by the Bangladesh Bureau of Statistics (BBS, 2011c). The economic data consisted of household material and toilet facilities were also collected from the population and housing census of 2011 (BBS, 2011b).

Data on environmental parameters such as annual mean maximum and minimum temperature, annual mean rainfall, annual mean relative humidity and data on irrigated areas on the upazilas of the study area were collected from Bangladesh Bureau of

\section{Procedure of identification of the Risk Zones}

For identifying, the risk zones data on filariasis incidences, socio-economic and environmental variables have been used. Upazila wise thematic information of socio-economic and environmental variables (population density, literacy, no sanitary facilities, no toilet facilities, maximum temperature, minimum temperature, rainfall, relative humidity and irrigated areas) and filariasis endemicity was developed and the dataset was imported into

\section{RESULTS AND DISCUSSION}

\section{Socio-Economic and Geo-Environmental Risk} Model (SEGERM)

Sabesan et al., (2006) discovered the Geoenvironmental Risk Model (GERM) for filariasis. He noticed that filariasis transmission like other vector-borne infectious diseases is dependent on the geo-environmental variables (physiographic and climatic) at a macro level. These variables are either individually or in combination are known to be associated with the occurrence of filariasis. This approach was used to identify the areas to assess the potential risk of filariasis transmission in Tamil
Statistics (BBS), Bangladesh Meteorological Department (BMD). In addition, Bangladesh Agricultural Research Council (BARC) provided the necessary data in this respect.

Data on filariasis morbidity was collected from the filariasis hospital and centre for disease control located in Sayedpur of Nilphamari district. This hospital keeps the patient's attendance report in several register books containing the name, age, sex, address, disease diagnostics, etc.

The Local Government and Engineering Department (LGED) of Bangladesh provided spatial data. LGED is one of the leading organizations, which has developed a comprehensive spatial database for all upazilas of Bangladesh. The digital data of 58 upazilas of Rangpur Division (1:50 000 scale), were collected from LGED which depict many human and physical features. .

Statistical Package for Social Science (SPSS, Version 20) for geo-statistical analysis. The spatial regression model was applied to find out the spatial associations among the socio-economic and environmental variables with filariasis endemicity. Spatial regression integrates space and spatial relationships directly into their mathematics (ESRI, 2014).

Nadu, India (Sabesan et al., 2006).

FTRI for an area $=\sum_{i=1}^{5} Y i$

Where $=\mathrm{Y} 1+\mathrm{Y} 2+\mathrm{Y} 3+\mathrm{Y} 4+\mathrm{Y} 5+\mathrm{Y} 6$

$\mathrm{Y} 1, \mathrm{Y} 2, \mathrm{Y} 3, \mathrm{Y} 4, \mathrm{Y} 5$ and $\mathrm{Y} 6$ are the scores for Altitude, Temperature, Relative Humidity, Rainfall and Soil Type respectively. In order to indicate the FTRI for a locality as a standardized quantity, it is represented in terms of percentage as follows

$$
\text { FTRI of a locality }=\frac{\sum_{i=1}^{5} Y i}{\text { Maximum value of } \sum_{i=1}^{5} Y i \text { in the study area }} \times 100
$$

In the light of the approach stated above which was only geo-environmental based, an attempt has been made to develop a modified socio-economic and geo-environmental risk model which can be named as SEGERM for determining the areas of potential transmission of filariasis for the northern region of Bangladesh. So, this approach is clearly different in many ways from the approach of Sabesan et al. (2006). Variables have been selected through extensive literature survey. The ideas related to 
variables also have been captured through statistical analysis such as, factor analysis and partial regression analysis.

The model used the environmental and socioeconomic parameters, encompassing the ranges of different variables associated with transmission of filariasis as the ArcGIS (ArcMap) provided the natural breaks (Jenks) in its method of classification. With some low association, all the variables such as population density, literacy,

\section{Building the SEGERM model}

The relationship between the FTRI and the filarial morbidity in the study sites has been analysed using OLS (Ordinary Least Square) and GWR (Geographically Weighted Regression) and Spatial Regression (with FTRI as the independent variable, and filarial prevalence as the dependent variable). The dependent variable indicates the presence or housing type (kutcha and jhupri), toilet facilities (no sanitary facilities and having no toilet), temperature (maximum and minimum), rainfall, relative humidity, irrigated areas were found to be associated (based on factor analysis and spatial regression analysis) with the occurrence of filariasis in the study area. Later these variables were used for computing a composite index, to create a filariasis transmission risk index (FTRI) for developing the model (Sabesan et al., 2006)..

absence of filariasis transmission in the area. Figure 1 and Figure 2 show the StResid value of OLS and GWR model respectively. Table 1 shows the diagnostic statistics of OLS and GWR models. The global adjusted $\mathrm{r} 2$ is 0.59 and the local adjusted $\mathrm{r} 2$ is 0.75 which suggests that there has been large improvement in model performance. .

Table 1. Diagnostic statistics of the OLS and GWR model

\begin{tabular}{|c|c|c|c|c|c|}
\hline \multicolumn{3}{|c|}{ OLS model } & \multicolumn{3}{|c|}{ GWR model } \\
\hline Input Features & $:$ & Rangpur_Thana & Input Features & : & Rangpur_Thana \\
\hline Dependent Variable & $:$ & Filariiasis & Dependent Variable & $:$ & Filariiasis \\
\hline Independent Variable & $:$ & Risk Incdex & Independent Variable & : & Risk Incdex \\
\hline $\begin{array}{l}\text { Number of } \\
\text { observations }\end{array}$ & $:$ & 58 & $\begin{array}{c}\text { Number of } \\
\text { observations }\end{array}$ & : & 58 \\
\hline Multiple R-squared[d] & : & 0.59 & Multiple R-squared[d] & $:$ & 0.80 \\
\hline $\begin{array}{l}\text { Akaike's Information } \\
\text { Criterion (AICc) }[\mathrm{d}]\end{array}$ & $:$ & 564.58 & $\begin{array}{c}\text { Akaike's Information } \\
\text { Criterion }(\mathrm{AICc})[\mathrm{d}]\end{array}$ & $:$ & 542.41 \\
\hline Adjusted R-Squared [d]: & : & 0.58 & Adjusted R-Squared [d]: & : & 0.75 \\
\hline
\end{tabular}

The Geographically Weighted Regression (GWR) model analyzes the risk index predicted with 75 percent accuracy whether sites had filariasis patients or not. Akaike Information Criterion (AIC) is a different measure of goodness-of-fi. It is a measure of the 'relative distance' between the models that have the same independent variable (Charlton et al., 2009). As a general rule of thumb, models with smaller values of the AIC are preferable to models with higher values. Table 1 shows the OLS and GWR diagnostic statistics. AIC of OLS model is 564.58 and AIC of GWR model is 542.41 ; the difference of 22.44 is strong evidence of an improvement in the fit of the model.

In such case, the local coefficient estimates has also been mapped to realize the association of the risk index over the area. Figure 4 shows the variation in the coefficient estimates for the risk index. The influence of risk index in the model varies considerably over the study area, with a strong north-west direction. The range of the local coefficient is from 0.38 in the southernmost upazilas to 3.75 in the northernmost upazilas.

The results of the spatial regression analysis have helped to build a conceptual frame for filariasis transmission developed on the basis of current knowledge is shown in Figure 1.

Environmental factors mainly contributed to vector abundance and extrinsic incubation (of parasites) directly, as well as via vector survival. Once the environmental conditions are conducive, the social factors become the determinants contributing to the occurrence of flariasis at the micro level.

Based on the relative contribution of socio-economic and geo-environmental factors, a filariasis transmission risk model (SEGERM) was developed on a GIS platform. Depending on the FTRI values, the map was stratified into different spatial entities, from high "risk" ('red') to "non-risk" ('green'). The derived FTRI values ranged from 9 to 91 in the study sites. As shown in the map (Figure 5) there is no risk of transmission where the FTRI value is lower. The risk of transmission begins with FTRI value 62, and the potential risk rises with increasing value of FTRI. 


\section{Identifying Risk Zones}

Figure 5 depicts the Filariasis Transmission Risk Index (FTRI) for the study area. It can be observed that Nilphamari Sadar, most of the part of Domar, Jaldhaka, Kishorganj, Dinajpur Sadar, Sayedpur and some areas of Debiganj, Chrirbandar, Badarganj, Rangpur Sadar upazila are under 'very high risk zone'(FTRI-91). Most of the areas of Dimla, Debiganj, Thakurgaon Sadar, Birganj, Chrirbandar.

Nawabganj, Parbatipur, Badarganj, Taraganj, Mithapukur, Rangpur Sadar, Kaunia, Lalmonirhat Sadar, Gangachara and some areas of Pirganj, Kaharol, Birol, Fulbari upazila belonged to 'high risk zone'(FTRI-81). On the other hand, some parts of the Boda, Thakurgaon sadar, Pirganj, Baliadangi, Kaharole, Birganj, Parbatipur, Fulbari, Nawabganj, Mithapukur, Kaunia, Lalmonirhat Sadar, Gangachara, Kaliganj, Hatibandha and Dimla upazila fall under the FTRI index 60. Other upazilas are under moderate, low and very low risk zones.

The socio-economic and geo-environmental risk model developed on a GIS platform could be employed for spatial delimitation of filariasis risk on a macro scale, particularly to identify "non-risk" areas, more precisely (Sabesan, et al., 2006). Filariasis transmission is largely determined by the socio-economic and geo-environmental variables, and hence it is possible to identify the areas where risk of transmission can be determined on a macrolevel. Socio-economic and environmental conditions are widely conducive, to transmission efficiency; human factors (belief system, negligence, hygiene practices, lifestyles etc.) are also key determinants contributing to the local occurrence of flariasis.

The results obtained indicate that the "non-risk" transmission areas can be identified at national level using the SEGERM. This model is very effective for identifying non-risk areas and specially has importance for a country like Bangladesh where the disease is endemic in 34 out of 64 districts of the country. From the derived SEGERM model, it may be surmised that all people living in the high risk of infection may not carry infection. However, one can certainly expect that there exists a relatively high risk of filariasis transmission and the risk rises with the increasing values of FTRI (Sabesan, et al., 2006). 


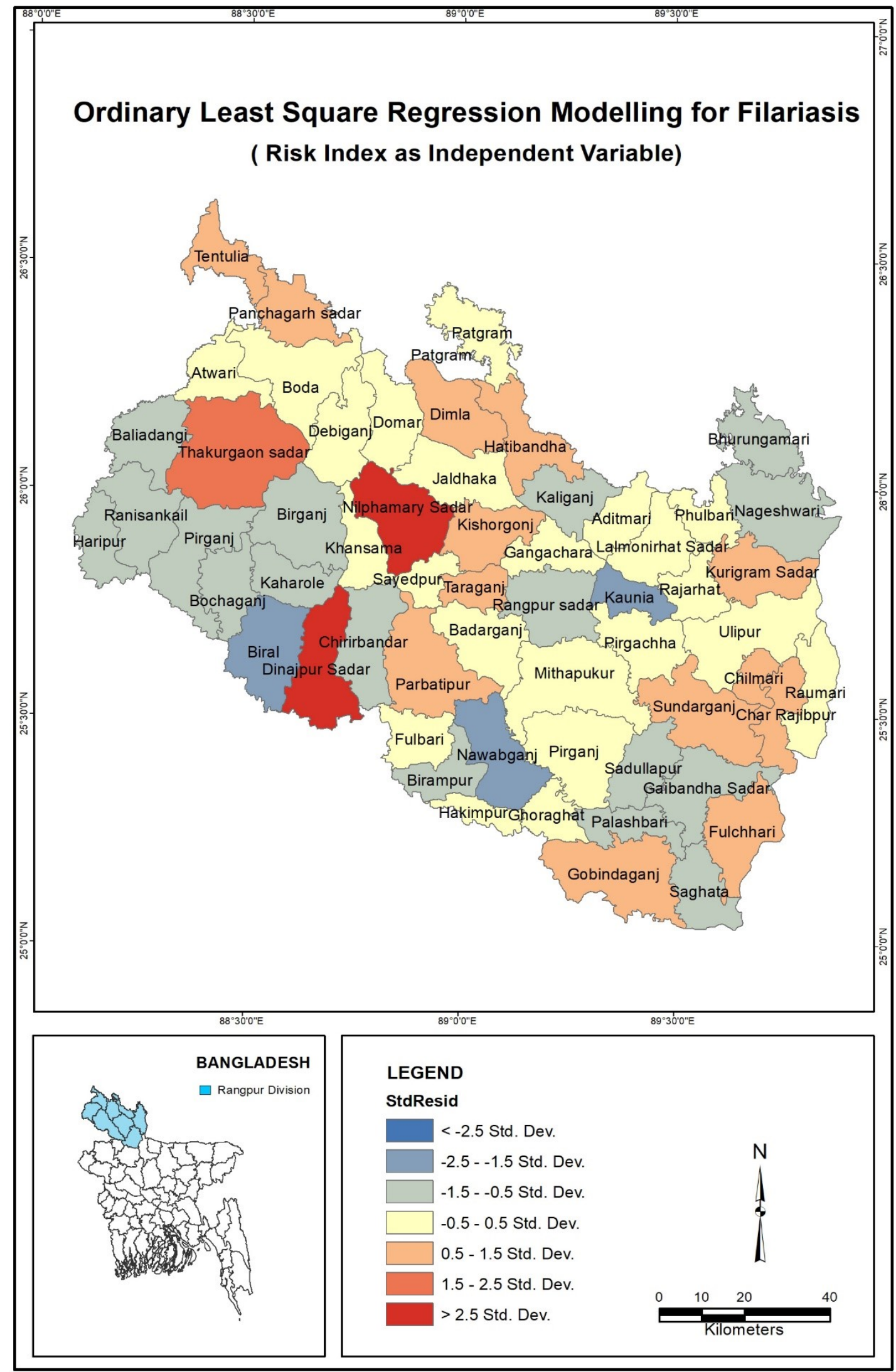

Figure 2 : Ordinay Least Square Regression Modelling for Filariasis

Data Source : Filaria Hospital, Sayedpur

Figure 2. Ordinay Least Square Regression Modelling for Filariasis 


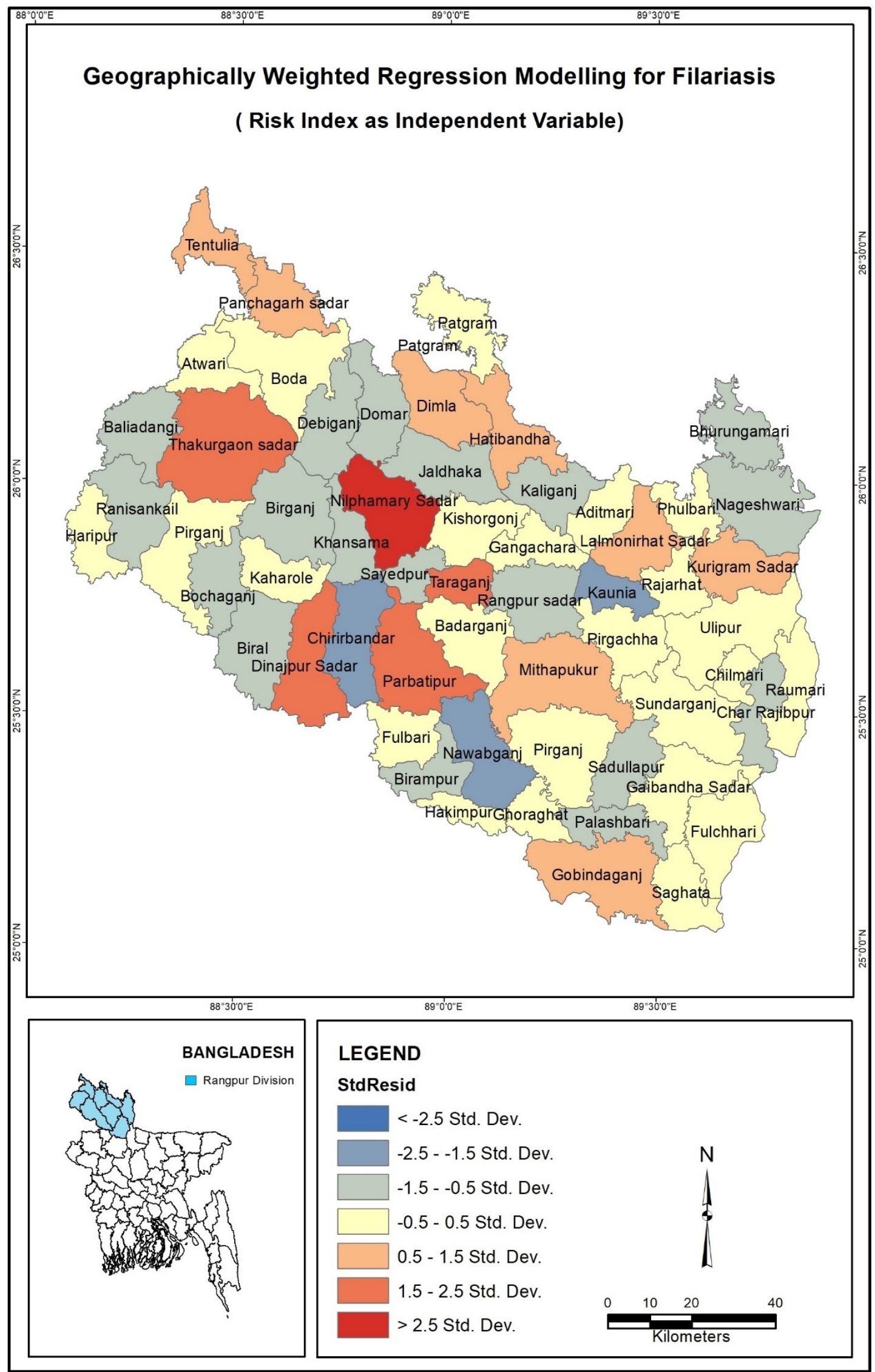

Figure 3 : Geographically Weighted Regression Modelling for Filariasis Data Source : Filaria Hospital, Sayedpur Figure 3. Geographically Weighted Regression Modeling for Filariasis. 


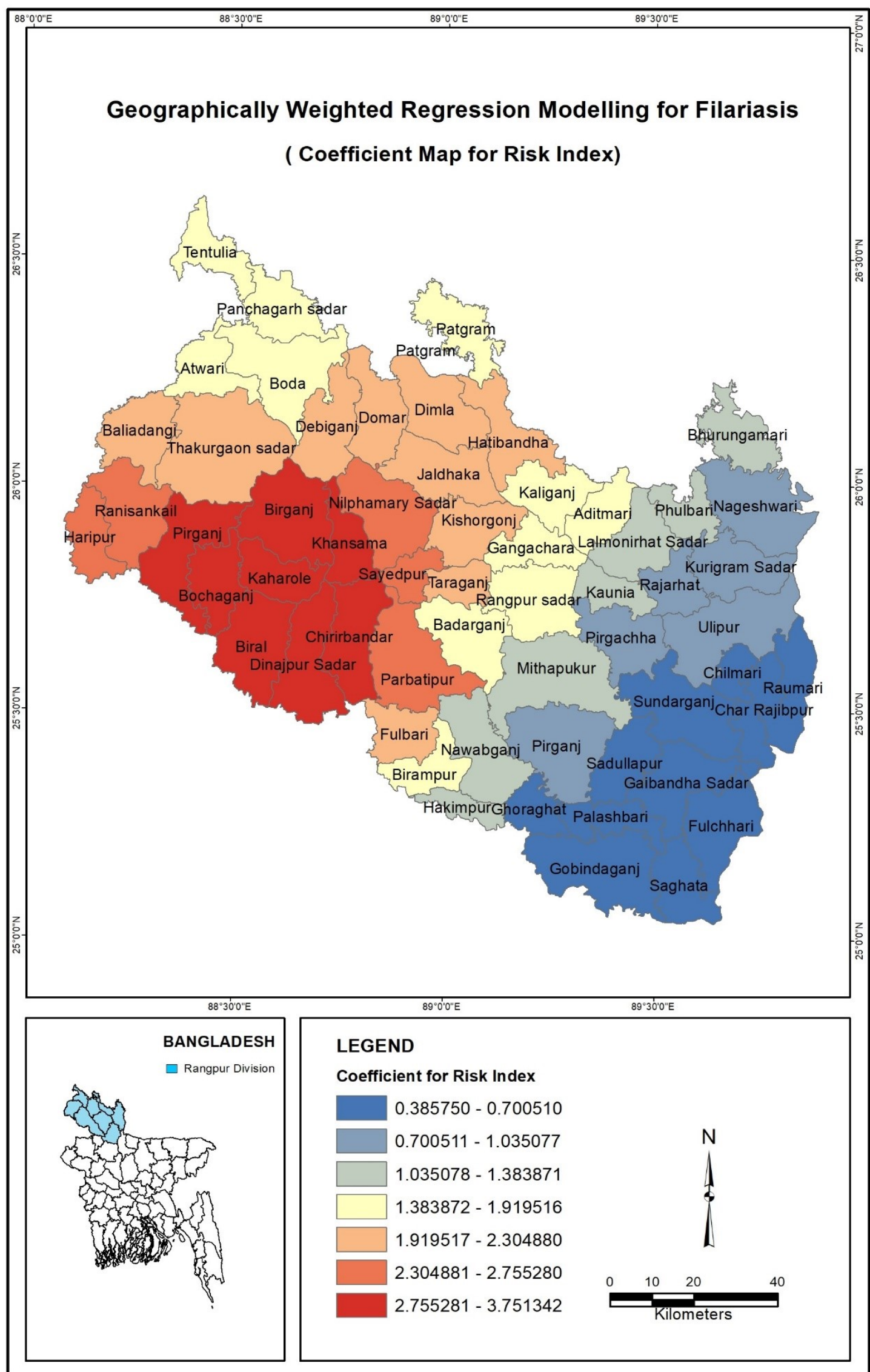

Figure 4 : Coefficient Map for Risk Index

Data Source : Filaria Hospital, Sayedpur

Figure 4. Coefficient Map for Risk Index 


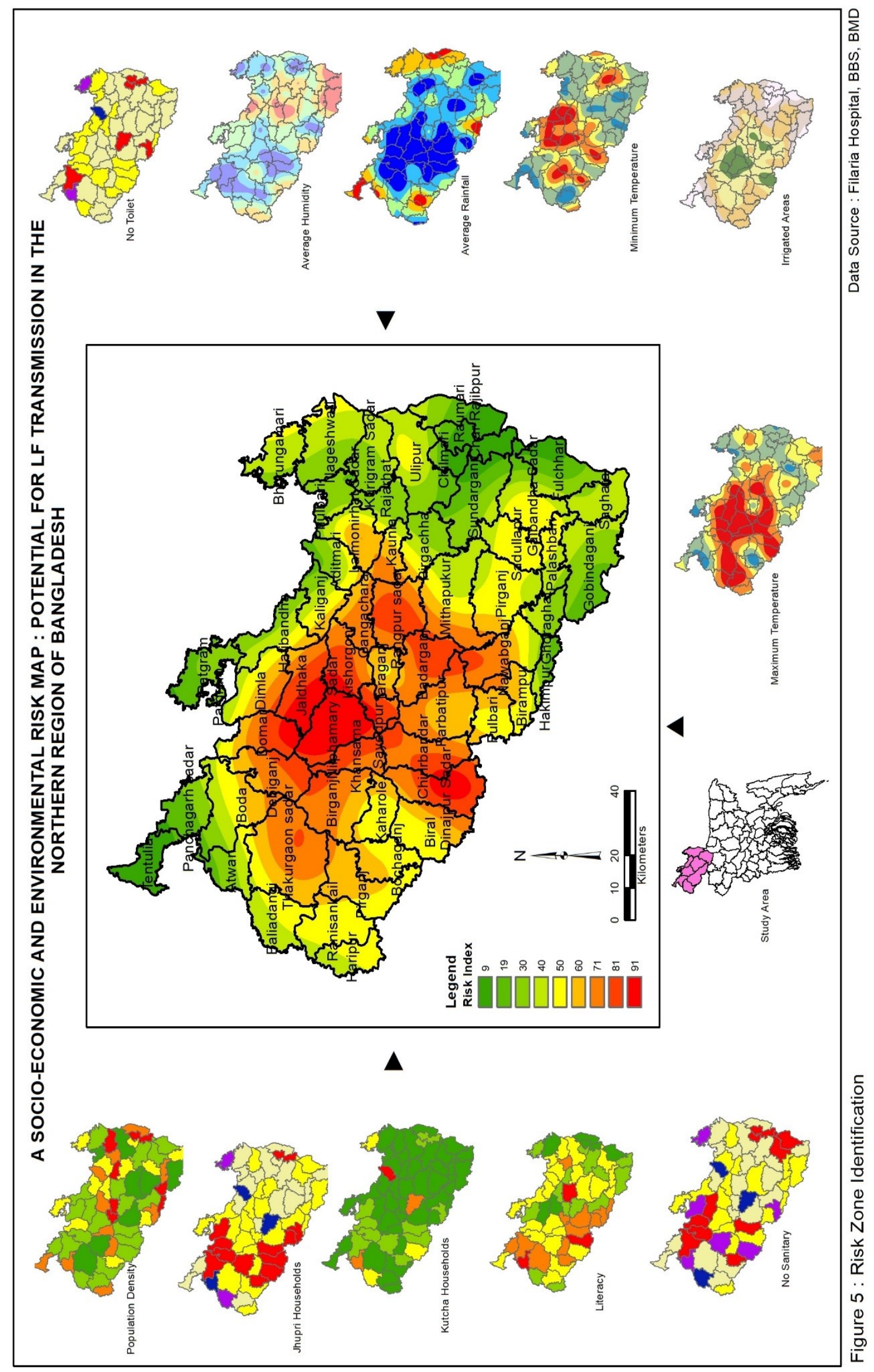

Figure 5. Risk Zone Indentification 


\section{CONCLUSION}

The risk concept is associated with the uncertainty or probability that a future event will occur within a certain period and given conditions, resulting in economic or social losses and with its eventual impact (Salcedo, 2004). The mapping of filariasis occurrence is demonstrated in this study and with the help of GIS, it was possible to map out the regions with the highest disease occurrences.

In this case, indicators made it possible to stratify the space using attribute data, thereby constituting a tool that could be used in filariasis control programmes. Risk mapping in epidemiology enables areas with a low or high risk of disease contamination to be localized, and provides a measure of risk differences between these regions (Garrido, et al., 2011). Analysing the relationship between endemic and socio-environmental variables one can examine the spatial risk areas.

It is observed that 'clusters' or 'lots' are the foci of filariasis transmission. The clusters, which were detected, could be essential for timely intervention to reduce the risk of resurgence. It can be opined that geospatial analysis can potentially be used as a tool for verifying eradication status and for confirming the reduction of transmission. This actually provides spatial decision support systems which may be used for filariasis elimination programmes and to explore possible environmental drivers of disease transmission of the country. The findings of the study suggest that one can explore the use of geospatial data for informing programme delivery (e.g. by identifying the size of clusters and delineating areas), and calculating the distance of influence on infection risk. The study has also the importance of assessing locally relevant risks for infection, which could vary significantly between places depending on cultural, societal, and environmental factors. The approach and results of this study are specifically relevant for Bangladesh but could also provide insight into filarial transmission and be relevant to society, culture, climate, environmental conditions. The present study observes that the Filariasis Transmission Risk Index (FTRI) successfully develops a risk map for the disease of the study area. The present study demonstrated that the filariasis transmission risk is mainly controlled by the socio-economic and environmental variables. The intensity of conformity between the determinant variables and the filariasis transmission risk is statistically significant and spatially important .Thus, the delineation of the areas and categorization of filariasis transmission risk zones using geostatistical modeling was highly reliable, accurate, quick, cost benefit and predictable for replacing the usual methods of predicting and mapping of filariasis in Bangladesh. Thus, the study depicts the application of GIS to the study of geostatistical modeling approach for stratification of filariasis transmission risk zones could be useful for preparing control programme towards the achievement of filariasis transmission control at the gross root level in the country

\section{Acknowledgements}

The authors are indebted to the Resident Medical Officer of the filariasis Hospital and Centre for Disease Control at Sayedpur and the Manager for providing the attribute data on filariasis morbidity and necessary information about the filariasis disease.

\section{REFERENCES}

[1] Bangladesh Bureau of Statistics (2011a). Population and housing census, Dhaka: Ministry of Planning.

[2] Bangladesh Bureau of Statistics (2011b). Population and housing census, Socio-Economic and Demographic Report, National Series, Volume-4, Dhaka: Ministry of Planning.

[3] Bangladesh Bureau of Statistics (2011c). Population and housing census, Community Series: Zila-Panchagarh, Thakurgaon, Dinajpur, Nilphamari, Lalmonirhat, Kurigram, Rangpur, Gaibandha. Dhaka: Ministry of Planning.

[4] Directorate General of Health Services (2014). Health Bulletin, Dhaka: Ministry of Health and Family Welfare.

[5] Durrheim, D. N., Wynd, S., Liese, B. and Gyapong, J. O. (2004). Lymphatic filariasisendemicity - an indicator of poverty?Tropical Medicine and International Health, volume 9 no 8 pp 843-845.

[6] ESRI (2014). Hot Spot Analysis (Getis-Ord Gi*), Retrieved from http://resources.arcgis.com/en/help/main/10.2/index.html\#//005p00000010000000, accessed on December 14, 2014.

[7] ESRI (2014). Ordinary Least Square, Retrieved from http://resources.arcgis.com/en/help/main/10.2/index.html\#//005p00000022000000, accessed on, December 14, 2014

[8] ESRI (2014). Geographically Weighted Regression, Retrieved fromhttp://resources. rcgis.com/en/help/main/10.2/index.html\#/Geographically Weighted_Regression_GWR/005p00000021000000/, accessed on December 16, 2014. 
[9] Fan, S. (2012). The spatial Temporal Prediction of Various Crime Types in Houston, TX Based on Hot-Spot Techniques.Unpublished Thesis.B.E. Central University.

[10] Fotheringham, AS, Charlton, M, 2009, Geographically Weighted Regression: A Tutorial on using GWR in ArcGis 9.3, Retrieve from https://geos.ed.ac.uk/ gisteac/fspat/gwr/gwr_arcgis/GWR_Tutorial.pdf, accessed on January 15, 2015.

[15] Garrido, Myriam \&Abrial, David \& De Goër De Herve, Jocelyn \&Dachian, Serguei\&Peyrard, Nathalie. (2011). Classification Method for Disease Risk Mapping Based on Discrete Hidden Markov Random Fields. Biostatistics (Oxford, England). 13. 241-55. 10.1093/biostatistics/kxr043

[11] IACIB (2014). Filariasis. Retrieve from http://iacib.org/filariasis/, accessed on May 20, 2014.

[12] Kanda, K. (2004). The quality of life among lymphedema patients due to lymphatic filariasis in three rural towns in Haiti. Graduate Theses and Dissertations. http://scholarcommons.usf.edu/etd/1105.

[13] Michael, E., Bundy, D.A., Greufell, B. T. (1996). Re-assessing the Global Prevalence and Distribution of LimphaticFilariasis. Parasitology, 112(pt.4), p.409:428.

[14] Ngwira, B.M.N., Tambala, P., Perez, A.M., Bowie, C. and Molyneux, D.H. (2007). The Distribution of Lymphatic Filariasis Infection in Malawi.Filaria Journal. 6:12, http://www.filariajournal.com/content/2/1/2012, accessed on July 10, 2013.

[15] Sabesan, S., Raju, H.K., Srividya, A. and Das, P.K. (2006). Delimitation of lymphatic filariasis transmission risk areas: a geo-environmental approach. Filaria Journal, 5: 12.

[16] Salcedo HE. (2004) Universidad del Valle. CursoTeoría y Análisis de losDesastresNaturales.Apuntes de Clase; (In press).

[17] Sasa, M. (1976). Human Filariasis, Baltimore: University Park Press.

[18] WHO (1995). Lymphatic filariasis: the disease and its control. World Health organization Geneva: Technical Report Series, 821:1-71.

[19] WHO (2001). Lymphatic filariasis. Wkly Epidemiol Rec 76: 149-154.

[20] WHO (2014b). Global Distribution of Fiariasis. Retrieve from http://www.wpro.who.int/mvp/topics/ntd/20120308/en/, accessed on December 15, 2014. 